\title{
Inhaltsverzeichnis
}

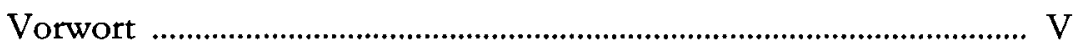

Jesus von Nazaret

Dieter Sänger

„Auf Betreiben der Vornehmsten unseres

Volkes" (losephus ant. Iud. XVIII 64). Zur Frage

einer jüdischen Beteiligung an der Kreuzigung Jesu

Paulus, der Apostel der Völker

Peter Lampe

Reticentia in der Argumentation:

Gal 3,10-1 2 als Stipatio Enthymematum

Christoph Burchard

Zu Gal 4, I-I I

Gerhard Sellin

Hagar und Sara. Religionsgeschichtliche

Hintergründe der Schriftallegorese Gal 4,2 I-3I

Dietrich-Alex Koch

Barnabas, Paulus und die Adressaten des Galaterbriefes

Samuel Vollenweider

Die Metamorphose des Gottessohns.

Zum epiphanialen Motivfeld in Phil 2,6-8 
Wolfgang Harnisch

Die paulinische Selbstempfehlung

als Plädoyer für den Gekreuzigten.

Rhetorisch-hermeneutische Erwägungen zu Phil 3

Ulrich B. Müller

Der Brief aus Ephesus.

Zeitliche Plazierung und theologische

Einordnung des Philipperbriefes im Rahmen der Paulusbriefe

Nikolaus Walter

Ekklesiologische Vorstellungen bei Paulus.

Mitbringsel aus Antiochia?

Ulrich Mell

Die Entstehungsgeschichte

der Trias „Glaube Hoffnung Liebe“ (1.Kor 13, I3)

Heinz-Wolfgang Kuhn

Qumran und Paulus. Unter traditionsgeschichtlichem

Aspekt ausgewählte Parallelen

Die synoptischen Evangelien und die Apostelgeschichte

Jürgen Roloff

Zur matthäischen Deutung der Winzerparabel (Mt 21,42-44)

Gerd Theißen

Die Verfolgung unter Agrippa I.

und die Autoritätsstruktur der Jerusalemer Gemeinde.

Eine Untersuchung zu Act 12,1-4 und Mk 10,35-45

\section{Das Johannesevangelium}

Ingo Broer

Das Weinwunder zu Kana (Joh 2,I-II)

und die Weinwunder der Antike 


\section{Andreas Lindemann}

Mose und Jesus Christus. Zum Verständnis

des Gesetzes im Johannesevangelium

Michael Theobald

"Spruchgut" im Johannesevangelium.

Bestandsaufnahme und weiterführende

Überlegungen zur Konzeption von J. Becker

Die Apokalypse des Jobannes

Jens-W. Taeger

Hell oder dunkel? Zur neueren Debatte

um die Auslegung des ersten apokalyptischen Reiters

Martin Karrer

Stärken des Randes: die Johannesoffenbarung

Zur Religionsgescbichte des Urcbristentums

Cilliers Breytenbach

Gnädigstimmen und opferkultische Sühne

im Urchristentum und seiner Umwelt

Helmut Merklein $\dagger$

Die heliopolitanische Trias

Annäberungen an eine Theologie des Urchristentums

Karlheinz Müller

Gibt es ein Judentum hinter den Juden?

Ein Nachtrag zu Ed Parish Sanders' Theorie

vom "Convenantal Nomism"

François Vouga

Das Problem der Selbstdefinition und

der theologischen Einheit des frühen Christentums 
Heikki Räisänen

"Theologie des Neuen Testaments"

und ihre Alternativen heute

Otto Merk

Das Urchristentum im Werk von

Werner Georg Kümmel. Ein Überblick

Abbildungsnachweis

Mitarbeiterverzeichnis

Register $56 I$

Anhang

Ulrich Mell

Bibliographie Jürgen Becker (1995-1998) 